\title{
RPGJEIS: Uma ferramenta de autoria De Jogos Educativos Do Gênero Role-Play Game Para o Auxílio Do Letramento De Crianças Surdas
}

\author{
Ludmilla Fernandes Oliveira Galvão ${ }^{1}$, Laura Sánchez García ${ }^{1}$, Tanya Amara Felipe ${ }^{2}$ \\ ${ }^{1}$ Programa de Pós-Graduação em Informática - Universidade Federal do Paraná (UFPR) \\ Curitiba - PR - Brasil. \\ ${ }^{2}$ Instituto Nacional de Educação de Surdos (INES) \\ Rio de Janeiro - RJ - Brasil. \\ \{ludmillagalvaol, sg.laura, tanyafelipe\}egmail.com
}

\begin{abstract}
Resumo. A comunidade Surda sofre com a falta de práticas inclusivas na educação brasileira. Uma forma de auxiliar o processo de ensino e aprendizagem é a utilização de jogos. Mesmo havendo jogos para auxiliar o letramento de crianças Surdas, muitos não são acessíveis. Isso se deve pela desvinculação do conteúdo educativo do jogo com especialistas da Educação, que muitas vezes não possuem conhecimentos avançados em Desenvolvimento de Jogos. $O$ objetivo dessa pesquisa é a especificação conceitual da ferramenta de autoria RPGJEIS, visando a confecção de jogos educativos para crianças de 4 e 5 anos do gênero RPG eletrônico, e requisitos e recomendações para criação de jogos acessíveis e alinhados com objetivos de aprendizado da Educação Infantil.
\end{abstract}

\section{Motivação}

Um dos principais desafios na Educação Básica brasileira é como formular estratégias para melhorar a Educação Pública Inclusiva. Apesar de haver orientações pedagógicas que assegurem instruções para as crianças com deficiência, transtornos globais de desenvolvimento e altas habilidades/superdotação [BRASIL e CNE 2010, AUGUSTO 2013, MEC 2017], ainda existem barreiras para tornar as políticas de inclusão uma realidade nas escolas. Em particular, as crianças Surdas não são alfabetizadas na Língua Portuguesa escrita por meio de um método natural para seu tipo de comunicação visual-espacial [Dias 2012]. E, quando se trata da educação de Surdos é necessário resguardar o direito de serem alfabetizadas na sua língua materna, neste caso a língua de sinais brasileira, a Libras [de Quadros e Schmiedt 2006], por meio da Educação Bilíngue.

A fim de apoiar o processo de ensino e aprendizagem, considera-se que jogos digitais possuem um grande potencial como ferramentas educacionais [de Oliveira et al. 2014, Martins et al. 2019]. Nesse contexto, os jogos digitais, em especial os educativos, podem auxiliar a aquisição de conhecimento por crianças Surdas [Chuan e Guardino 2016], levando em consideração a "importância do letramento para o desenvolvimento de habilidades cognitivas e sociais" [Aristizábal et al. 2017]. Apesar de haver jogos para auxiliar o letramento de crianças Surdas, muitos ainda dependem de textos em mecânicas para a participação no jogo, criando barreiras e resistência para as crianças Surdas e o seu processo de aprendizagem. Outro agravante é a ausência de educadores no processo de construção de jogos educativos, a fim de que o conteúdo apresentado no jogo seja adequado e efetivo. 
VIII Congresso Brasileiro de Informática na Educação (CBIE 2019)

Anais dos Workshops do VIII Congresso Brasileiro de Informática na Educação (WCBIE 2019)

Levando isso em consideração, o objetivo dessa pesquisa é, baseando-se no Framework Conceitual de [Canteri 2019], esse trabalho visa a especificação conceitual de uma ferramenta de autoria utilizando o gênero RPG (Role-Play Game ou jogo de interpretação de papéis) eletrônico, intitulada RPGJEIS (Jogos RPG para a Educação Infantil de Surdos). A RPGJEIS tem por objetivo ser simples para que não especialistas em desenvolvimento de jogos consigam utilizá-la na confecção de jogos para crianças Surdas. Ao mesmo tempo, também irá apresentar orientações para que especialistas consigam desenvolver jogos adequados e acessíveis para crianças de 0 a 6 anos. Além disso, a RPGJEIS contará com um ambiente no qual os jogos desenvolvidos na ferramenta poderão ser acessados via $w e b$ pelas crianças Surdas.

O RPG eletrônico foi escolhido por não ter sido encontrado jogos educativos desse gênero no Mapeamento Sistemático da Literatura (MSL) realizado em 2018 e por ser um gênero que estimula a cooperação, criatividade, interatividade e interdisciplinaridade [Grando e Tarouco 2008], habilidades intrínsecas para o desenvolvimento infantil [BRASIL e CNE 2010, AUGUSTO 2013, MEC 2017]. Além disso, o gênero vai ao encontro dos objetivos de aprendizagem propostos pelos documentos normativos da Educação Infantil do Ministério da Educação (MEC) [BRASIL e CNE 2010, AUGUSTO 2013, MEC 2017] e ao plano de curso para o Ensino Infantil de Crianças Surdas de 4 e 5 anos proposto por [Cruz et al. 2015]. Isso se aplica na medida em que o RPG eletrônico: é um gênero com alto teor narrativo, atendendo à contação de histórias propostas no Ensino Infantil [BRASIL e CNE 2010, AUGUSTO 2013, MEC 2017, Cruz et al. 2015], exercitando a imaginação , o interesse cultural e a empatia da criança; exercita a exploração [BRASIL e CNE 2010, AUGUSTO 2013, MEC 2017], assim como a orientação espacial cruz2015; pode desenvolver a socialização [BRASIL e CNE 2010, AUGUSTO 2013, MEC 2017, Cruz et al. 2015]; caracteriza-se como a interpretação de papéis cruz2015.

Adicionalmente ao objetivo desse trabalho, foram desenvolvidos requisitos e recomendações baseados em documentações pedagógicas do Ministério da Educação (MEC). O intuito dos requisitos e recomendações é oferecer um direcionamento em que deve ser feito para que os jogos educativos sejam acessíveis e interessantes para as crianças Surdas (0 a 6 anos), além de proporcionar consciência de direitos humanos e cidadania, estimular o aprendizado e a imersão no jogo.

Como prova de conceito, a fim de avaliar as metodologias propostas, será desenvolvido um jogo educativo do gênero RPG eletrônico para auxiliar no letramento de crianças Surdas entre 4 e 5 anos, se apoiando nas metodologias propostas. Esse jogo possui por intuito apresentar a fauna e flora típica pré-amazônica e valorizar a cultura indígena da tribo Urubu-Kaapor, através da sinalização de mãos em Libras e sua respectiva representação em português.

Portanto, o presente trabalho tem como hipótese de trabalho que "o gênero de jogo RPG eletrônico pode auxiliar na construção de conhecimento na Educação Infantil pelas crianças Surdas de 4 e 5 anos".

\section{Metodologia}

A proposta dessa pesquisa é a especificação conceitual de uma ferramenta de autoria para o desenvolvimento de jogos educativos de RPG eletrônico para auxiliar o letramento de 
VIII Congresso Brasileiro de Informática na Educação (CBIE 2019)

Anais dos Workshops do VIII Congresso Brasileiro de Informática na Educação (WCBIE 2019)

crianças Surdas de 4 e 5 anos. Essa ferramenta deverá: Ter acesso livre e gratuito; Ser simples e prática de se utilizar, não exigindo conhecimentos avançados em Desenvolvimento de Jogos; Produzir jogos educativos úteis e significativos para o contexto educativo de crianças Surdas, alinhados com as orientações pedagógicas do MEC e o plano de curso para o Ensino Infantil de crianças Surdas de 4 e 5 anos proposto por [Cruz et al. 2015].

Nas próximas subseções serão apresentadas as três contribuições dessa pesquisa: Os requisitos e recomendações baseados nas orientações pedagógicas do MEC, a ferramenta de autoria RPGJEIS e o jogo RPG eletrônico.

\subsection{Requisitos e Recomendações Baseados nas Orientações Pedagógicas do MEC}

O desenvolvimento dos requisitos e recomendações teve como fontes principais as Diretrizes Curriculares Nacionais para a Educação Infantil (DCNEI) [BRASIL e CNE 2010], as Novas diretrizes para a Educação Infantil (NDEI) [AUGUSTO 2013] e a Base Nacional Comum Curricular (BNCC) [MEC 2017]. Após a leitura e a análise dos três documentos, foram selecionados trechos de cada um deles que apresentavam orientações sobre o ensino e a aprendizagem para a Educação Infantil, elaborando-se, em seguida, um conjunto de diretrizes. Após a formulação das diretrizes, buscou-se sintetizá-las, retirando redundâncias ou agrupando por finalidade.

A fim de validar as diretrizes, foi realizada uma reunião com os participantes do grupo de pesquisa que atuam em trabalhos envolvendo a Libras, na qual foram levantados feedbacks para seu aprimoramento. As principais sugestões foram a divisão das diretrizes entre requisitos, de caráter obrigatório, e recomendações, de caráter sugestivo, além da padronização das especificações.

Os requisitos foram classificados em 3 categorias: "Aprendizagem", sobre questões de aprendizado e desenvolvimento das crianças; "Implementação", com requisitos sobre questões técnicas na modelagem do jogo, como gameplay; "Ética, Diversidade e Acessibilidade", compreendendo os requisitos com carga moral/ética ou associados às diversidades culturais, linguísticas de forma geral, entre outras. Já as recomendações foram divididas de acordo com os 5 campos de experiência e aprendizagem propostos pelo MEC, "Espaços, tempos, quantidades, relações e transformações", "Traços, sons, cores e formas", "O eu, o outro e nós", "Escuta, fala, pensamento e imaginação" e "Corpo, gestos e movimentos".

Ao final do processo de refinamento foram contabilizados 42 requisitos, sendo 19 referentes à "Aprendizagem", 18 referentes à "Implementação" e 10 referentes à "Ética, Diversidade e Acessibilidade" e 27 recomendações, sendo 8 recomendações referentes ao campo "Espaços, tempos, quantidades, relações e transformações", 8 referentes ao campo "Traços, sons, cores e formas", 8 referentes ao campo "O eu, o outro e nós", 7 referentes ao campo "Escuta, fala, pensamento e imaginação" e 6 referentes ao campo "Corpo, gestos e movimentos". Vale ressaltar que um requisito ou recomendação pode pertencer a mais de uma categoria. Os requisitos e recomendações podem ser vistos em sua completude no link (https://bit.ly/2lMgyjr).

\subsection{RPGJEIS: ferramenta de autoria para o Gênero RPG Eletrônico}

A RPGJEIS será uma ferramenta de autoria composta por dois ambientes: um "Ambiente de Criação" de jogos RPG eletrônico; e um "Ambiente de Acesso" para o acesso 
VIII Congresso Brasileiro de Informática na Educação (CBIE 2019)

Anais dos Workshops do VIII Congresso Brasileiro de Informática na Educação (WCBIE 2019)

e compartilhamento dos jogos confeccionados. O "Ambiente de Criação" é objetivado principalmente para os pessoas com pouca ou nenhuma experiência em Desenvolvimento de Jogos, como educadores. Apesar disso, os requisitos e recomendações presentes nesse "Ambiente de Criação" podem ser utilizados por desenvolvedores de jogos, para auxiliar os mesmos na confecção de seus jogos utilizando outras plataformas e/ou linguagens de programação.

Para a confecção do jogo, o usuário deverá percorrer as 4 etapas propostas por [Canteri 2019] e adaptadas no contexto dessa pesquisa sendo elas: 'Ensino e Aprendizagem", responsável pela definição do conteúdo educativo e história do jogo; "Gráficos e Interface", responsável pela definição das imagens que serão utilizadas para a construção do jogo; "Jogabilidade e Mecânicas", responsável pela definição das mecânicas do jogo, no qual o usuário irá incluir os elementos do jogo no(s) cenário(s) e conectá-los com o que se pretende ensinar; e "Aprendiz e Tutoria", responsável por verificar a aprendizagem do aluno e auxiliá-lo quando o mesmo apresentar dificuldades.

O segundo ambiente, o "Ambiente de Acesso" é o responsável por apresentar os jogos RPG eletrônico disponíveis na ferramenta de autoria, confeccionados no "Ambiente de Criação". É nesse ambiente que as crianças Surdas e os educadores poderão visualizar e jogar os jogos confeccionados por diversos usuários do sistema, agrupados pelos campos de experiência e aprendizagem do MEC.

A RPGJEIS consistirá numa ferramenta de autoria composta por 3 Módulos, adaptados de [Canteri 2019]:

- Módulo Plataforma Web: Consiste na plataforma na qual os usuários irão construir e acessar os jogos RPG eletrônico;

- Módulo Banco de Dados: É aonde as imagens que serão inseridas no jogo e os jogos RPG eletrônico cadastrados serão armazenados. A fim de evitar a inclusão de imagens indevidas, o administrador do sistema fará manutenções periódicas;

- Módulo Gerador de Jogos: Será o responsável por gerar o jogo RPG eletrônico a partir dos parâmetros definidos pelo usuário e das imagens disponíveis no banco de dados.

A partir desses 3 módulos, que interligados entre si formam a ferramenta de autoria RPGJEIS, é possível a construção de um jogo educativo do gênero RPG eletrônico. Como prova de conceito, será implementado um jogo do gênero RPG eletrônico seguindo os requisitos e recomendações construídos e na metodologia proposta pela RPGJEIS. O jogo, após desenvolvido, será testado em crianças Surdas na faixa etária entre 4 e 5 anos do INES (Instituto Nacional de Educação dos Surdos).

\section{Resultados Esperados}

Espera-se que tanto pessoas experientes quanto inexperientes em Desenvolvimento de Jogos consigam tirar proveito da RPGJEIS. Os usuários mais experientes, através do uso dos requisitos e recomendações baseados nas orientações do MEC, a fim de construir jogos educativos adequados em termos de acessibilidade e conteúdo programático para crianças de 0 a 6 anos. E os usuários menos experientes, com o uso de uma ferramenta de autoria simples para a concepção e compartilhamento de jogos do gênero RPG eletrônico para crianças Surdas de 4 e 5 anos. 
VIII Congresso Brasileiro de Informática na Educação (CBIE 2019)

Anais dos Workshops do VIII Congresso Brasileiro de Informática na Educação (WCBIE 2019)

A partir da metodologia proposta pela RPGJEIS, é esperado que surjam mais jogos educativos acessíveis e dentro do contexto educativo das crianças Surdas, a fim de auxiliar o processo de ensino e aprendizagem na Educação Inclusiva e na Educação Bilíngue.

Como etapas já concluídas do trabalho, tem-se a confecção dos requisitos e recomendações e a especificação conceitual da RPGJEIS. Como etapas futuras do trabalho, é pretendido o aperfeiçoamento dos requisitos e recomendações, adicionando mais duas colunas, uma de "Sugestões de Implementação"e "Exemplo de Jogo", a fim de ficar mais claro para o desenvolvedor a aplicação de um determinado requisito ou recomendação. Além disso, a implementação e avaliação do jogo RPG eletrônico com crianças Surdas de 4 e 5 anos, a fim de avaliar as metodologias propostas.

\section{Referências}

Aristizábal, L. F., Cano, S., e Collazos, C. (2017). Using storytelling to support the education of deaf children: A systematic literature review. In International Conference of Design, User Experience, and Usability, pages 371-382. Springer.

AUGUSTO, S. d. O. (2013). A experiência de aprender na educação infantil. BRASIL, MEC/SEB. Novas Diretrizes para a Educação Infantil. TV escola/Salto para o futuro, ano XXIII, (9):19-28.

BRASIL, M. e CNE, C. (2010). Diretrizes curriculares nacionais para a educação infantil. Resolução CEB-CNE, (01).

Canteri, R. d. P. (2019). Jeis - framework conceitual e ferramenta de autoria para a construção de jogos digitais para educação infantil de surdos. No prelo.

Chuan, C.-H. e Guardino, C. A. (2016). Designing smartsignplay: An interactive and intelligent american sign language app for children who are deaf or hard of hearing and their families. In Companion publication of the 21st international conference on intelligent user interfaces, pages 45-48. ACM.

Cruz, A. M., Miranda, J., Rossi, H., Maia, M. C., Mojon, Q. H., e Felipe, T. A. (2015). Plano de curso de libras anual educação infantil, 4 e 5 anos. Relatório técnico.

de Oliveira, G. A., de Bettio, R. W., Rodarte, A. P., Ferrari, F. B., et al. (2014). Grubibots educacional: jogo para o ensino de algoritmos na educação básica. In Brazilian Symposium on Computers in Education (Simpósio Brasileiro de Informática na Educação-SBIE), volume 25, page 584.

de Quadros, R. M. e Schmiedt, M. L. (2006). Ideias para ensinar português para alunos surdos. Brasília: Mec, SEESP.

Dias, A. F. A. (2012). Lingua portuguesa e libras: duas linguas que precisam conviver lado a lado. Revista Escrita, (15).

Grando, A. e Tarouco, L. M. R. (2008). O uso de jogos educacionais do tipo rpg na educação. RENOTE, 6(1).

Martins, R. S., Raulino, F., Burlamaqui, A., e Burlamaqui, A. (2019). Sgddedu: A model of short game design document for digital educational games. International Journal for Innovation Education and Research, 7(2):167-180.

MEC, M. d. E. (2017). Base nacional comum curricular: educação é a base. 